\title{
Body protective compound- I 57 enhances alkali-burn wound healing in vivo and promotes proliferation, migration, and angiogenesis in vitro
}

This article was published in the following Dove Press journal:

Drug Design, Development and Therapy

30 April 2015

Number of times this article has been viewed

\author{
Tonglie Huangl,* \\ Kuo Zhang ${ }^{2, *}$ \\ Lijuan Sun ${ }^{3}$ \\ Xiaochang Xue' \\ Cun Zhang' \\ Zhen Shu' \\ $\mathrm{Nan} \mathrm{Mu}^{\prime}$ \\ Jintao $\mathrm{Gu}^{\prime}$ \\ Wangqian Zhang' \\ Yukun Wang' \\ Yingqi Zhang' \\ Wei Zhang'
}

'State Key Laboratory of Cancer Biology, Department of Biopharmaceutics, School of Pharmacy, The Fourth Military Medical University, ${ }^{2}$ National Engineering Research Center for Miniaturized Detection Systems, School of Life Sciences, Northwest University, ${ }^{3}$ Department of Ophthalmology, Xijing Hospital, The Fourth Military Medical University, Xi'an, People's Republic of China

*These authors contributed equally to this work
Correspondence: Yingqi Zhang; Wei Zhang

State Key Laboratory of Cancer Biology, Department of Biopharmaceutics, School of Pharmacy, The Fourth Military Medical University, Chang-Le Xi Street \#169, Xi'an 710032, People's Republic of China $\mathrm{Tel} / \mathrm{Fax}+86298477$ 4773;

+862984773488

Email zhangyqh@fmmu.edu.cn; zhangw90@fmmu.edu.cn

\begin{abstract}
Chemical burns take up a high proportion of burns admissions and can penetrate deep into tissues. Various reagents have been applied in the treatment of skin chemical burns; however, no optimal reagent for skin chemical burns currently exists. The present study investigated the effect of topical body protective compound (BPC)-157 treatment on skin wound healing, using an alkali burn rat model. Topical treatment with BPC-157 was shown to accelerate wound closure following an alkali burn. Histological examination of skin sections with hematoxylin-eosin and Masson staining showed better granulation tissue formation, reepithelialization, dermal remodeling, and a higher extent of collagen deposition when compared to the model control group on the 18 th day postwounding. BPC-157 could promote vascular endothelial growth factor expression in wounded skin tissues. Furthermore, 3-(4,5-dimethylthiazol-2-yl)-2,5-diphenyltetrazolium bromide and cell cycle analysis demonstrated that BPC-157 enhanced the proliferation of human umbilical vein endothelial cells (HUVECs). Transwell assay and wound healing assay showed that BPC-157 significantly promoted migration of HUVECs. We also observed that BPC-157 upregulated the expression of VEGF-a and accelerated vascular tube formation in vitro. Moreover, further studies suggested that BPC-157 regulated the phosphorylation level of extracellular signal-regulated kinases 1 and 2 (ERK1/2) as well as its downstream targets, including c-Fos, c-Jun, and Egr-1, which are key molecules involved in cell growth, migration, and angiogenesis. Altogether, our results indicated that BPC-157 treatment may accelerate wound healing in a model of alkali burn-induced skin injury. The therapeutic mechanism may be associated with accelerated granulation tissue formation, reepithelialization, dermal remodeling, and collagen deposition through ERK1/2 signaling pathway.
\end{abstract}

Keywords: pentadecapeptide BPC-157, wound healing, human umbilical vein endothelial cells, ERK1/2 signaling pathway

\section{Introduction}

Wound healing is a very complicated pathophysiologic process. Although the process of healing is continuous, it may be arbitrarily divided into four phases: 1) coagulation and hemostasis; 2) inflammation; 3) proliferation; and 4) wound remodeling with scar tissue formation. ${ }^{1}$ Much effort has been focused on wound care, with an emphasis on new therapeutic approaches and the development of technologies for acute and chronic wound management.

Emerging evidences suggested that several peptides play critical roles in the inflammatory response and wound healing. Many growth factors such as transforming growth factor (TGF)- $\beta,{ }^{2}$ platelet-derived growth factor (PDGF), ${ }^{3}$ epidermal growth factor (EGF), ${ }^{4}$ and fibroblast growth factor (FGF), ${ }^{5}$ as well as interleukin (IL)- $1^{6}$ and tumor necrosis factor (TNF), ${ }^{7}$ have been evaluated in a wide spectrum of in vivo and in vitro experiments 
to observe their effects on different elements included in the healing process. TGF- $\beta$, PDGF, EGF, and FGF have been shown to stimulate infiltration of inflammatory cells into the wound space. ${ }^{2-4}$ These growth factors induce proliferation of keratinocytes and fibroblasts, lead to new formation of capillaries in the granulation tissue, and modulate extracellular matrix deposition and reconstitution of the injured area. ${ }^{2-5}$ The topical application of growth factors was successful in accelerating healing of full-thickness wound in normal mice. ${ }^{8,9}$

The pentadecapeptide body protective compound (BPC)157 ( $M r$ 1419), with the sequence Gly-Glu-Pro-Pro-Pro-GlyLys-Pro-Ala-Asp-Asp-Ala-Gly-Leu-Val, a 15-amino acid fragment of the BPC peptide in gastric juice, is thought to be essential for BPC's activity and has been fully characterized and investigated. BPC-157 has many functions, such as attenuating liver, ${ }^{10}$ lung, ${ }^{11}$ colon, ${ }^{12}$ and gastric lesions, ${ }^{13}$ displaying antianxiety and antidepressant effects, ${ }^{14}$ improving angiogenesis and wound healing, ${ }^{15}$ reversing 1-methyl4-phenvl-1,2,3,6-tetrahvdropvridine (MPTP)-specific motor abnormalities in Parkinson's disease models, ${ }^{16}$ having mucosal protective and anti-inflammatory effects, ${ }^{17}$ particularly those affecting the dopamine system, ${ }^{18}$ and persistent activity. ${ }^{19}$ BPC-157 appears to be beneficial to almost all organ systems in various species at very low dosages (mostly milligrams to nanograms per kilogram).

Previous experiments strongly suggested its involvement in experimental gastric ulcer healing. ${ }^{10,18,20-25}$ BPC-157 also stimulates healing of segmental osteoperiosteal bone defects when either given locally by the percutaneous mode into the bone defect or applied intramuscularly. ${ }^{26}$ Moreover, BPC-157 solution was shown to stimulate corneal wound healing. ${ }^{27}$ However, the underlying mechanisms of the wound healing effects of BPC-157 have not been fully clarified.

The present study aimed to investigate the wound healing effects of synthesized BPC-157 on alkali-burned rats and elucidate its mechanisms of action. Our results demonstrated that BPC-157 possessed wound healing effects on alkaliburned rats, and BPC-157 promotes proliferation, migration, and tube formation of human umbilical vein endothelial cells (HUVECs) through the extracellular signal-regulated kinases 1 and $2($ ERK1/2) signaling pathway.

\section{Materials and methods}

\section{Ethic statements}

The animal studies were carried out in strict accordance with the Detailed Rules for the Administration of Animal Experiments for Medical Research Purposes issued by the Ministry of Health of the People's Republic of China and were approved by the Animal Experiment Administration Committee of The Fourth Military Medical University. All efforts were made to keep pain and suffering to a minimum.

\section{Drugs}

Medication, without carrier or peptidase inhibitor, included stable gastric pentadecapeptide BPC-157 (a partial sequence of the human gastric juice protein BPC, freely soluble in water at $\mathrm{pH} 7.0$ and in saline). It was prepared as a peptide with $99 \%$ (high-performance liquid chromatography) purity (1-desGly peptide was the main impurity; manufactured by our laboratory, GEPPPGKPADDAGLV, relative molecular mass: 1,419). Accordingly, basic FGF (bFGF) (EssexBio, Zhuhai, People's Republic of China) dissolved in saline was used.

\section{Animal model}

Male Sprague Dawley rats $(n=58)$ weighing $160 \mathrm{~g}-220 \mathrm{~g}$ were chosen for the experiments. The rats were anesthetized with intraperitoneal injection of pentobarbital sodium $(50 \mathrm{mg} / \mathrm{kg})$, and dorsal hair was shaved and depilated with hair removal cream. The skin alkali burn was made by placing a $9 \mathrm{~cm}^{2}$ piece of filter paper soaked in $2 \mathrm{M} \mathrm{NaOH}$ on each animal's skin for 75 seconds. Then the animals received an intraperitoneal injection of saline $(100 \mathrm{~mL} / \mathrm{kg})$ and were placed in individual cages for recovery. To confirm the degree of burns, histopathological samples were taken from eight rats. Then all animals were randomly divided into five groups $(n=10)$ as follows: group I (model control) rats were administrated plain hydrogel alone; group II: $200 \mathrm{ng} / \mathrm{mL}$ bFGF, group III: $200 \mathrm{ng} / \mathrm{mL}$ BPC-157, group IV: $400 \mathrm{ng} / \mathrm{mL}$ BPC-157, and group V: $800 \mathrm{ng} / \mathrm{mL}$ BPC-157. The hydrogels were applied topically using cotton Q-tip swabs twice every day $(0.5 \mathrm{~mL}$ per wound per time) for 18 days. The rats were bandaged with petroleum jelly-impregnated gauze. All rats used in this study were kept at a humidity of $50 \%-60 \%$ and a temperature of $25^{\circ} \mathrm{C}$, with food and water being freely accessible. The general condition, behavior, and wound repair of all animals were checked daily. For wound repair evaluation, a transparent acetate sheet (Sigma-Aldrich, St Louis, MO, USA) was placed on the wound, its perimeter was traced and then sheared along the wound tracing, and the sheared part was weighed. Data are expressed as the percentage of wound closure (100 - weight of sheared acetate/weight of sheared acetate of the initial day $\times 100$ ).

\section{Histological examination}

Histological analysis of the skin was performed by taking $6 \mathrm{~mm}$ diameter biopsy punches from areas of interest. 
Samples were fixed in 10\% buffered formalin overnight at $4^{\circ} \mathrm{C}$, dehydrated with increasing concentrations of ethanol, embedded in paraffin, cut into $5 \mu \mathrm{m}$ sections, and stained with hematoxylin and eosin (HE) or Masson's Trichrome Stain Kit (Sigma-Aldrich). The stained sections were examined under inverse light microscopy.

\section{Cell culture}

HUVEC, HaCaT, and NIH 3T3 lines were obtained from the American Type Culture Collection. HUVECs and NIH 3T3 cells in Roswell Park Memorial Institute (RPMI) 1640 and HaCaT in Dulbecco's Minimum Essential Medium (DMEM)/F-12 medium were cultured in the indicated media supplemented with 10\% fetal bovine serum (FBS) and maintained at $37^{\circ} \mathrm{C}$ in a humidified environment with $5 \% \mathrm{CO}_{2}$.

\section{Cell proliferation assay}

To assess the influence of BPC-157 on cell growth, 3-(4,5-dimethylthiazol-2-yl)-2,5-diphenyltetrazolium bromide (MTT) cell proliferation assay was used. Briefly, cells were seeded in 96-well plates at $3 \times 10^{3}$ cells per well. On the next day, the cells were exposed to BPC-157 $(1 \mu \mathrm{g} / \mathrm{mL}$, $5 \mu \mathrm{g} / \mathrm{mL}$, and $10 \mu \mathrm{g} / \mathrm{mL}$ ). After BPC-157 treatment at different time points, the level of cell growth was measured using MTT. The cells were treated with MTT $(5 \mathrm{mg} / \mathrm{mL})$ for 4 hours at $37^{\circ} \mathrm{C}$. The supernatants were then removed and the formazan dye was dissolved in dimethyl sulfoxide (DMSO). The absorbance was measured using a microplate reader (Molecular Device, Menlo Park, CA, USA) at a wavelength of $490 \mathrm{~nm}$.

\section{Cell cycle analysis}

The position of the cells in the cell cycle was determined by flow cytometric analysis of the DNA content using propidium iodide. The cells were exposed to BPC-157 $(1 \mu \mathrm{g} / \mathrm{mL}, 5 \mu \mathrm{g} / \mathrm{mL}$, and $10 \mu \mathrm{g} / \mathrm{mL})$ for 48 hours. The cells were collected after treatment, washed twice with cold phosphate-buffered saline, and treated with $1 \mathrm{~mL}$ of cold citrate buffer ( $0.24 \mathrm{M}$ sucrose, $40 \mathrm{mM}$ sodium citrate, $\mathrm{pH}$ 7.6). The cells were then centrifuged and suspended in $0.1 \mathrm{~mL}$ of citrate buffer. Subsequently, $0.4 \mathrm{~mL}$ of a PI staining/ lysis solution ( $0.5 \% \mathrm{NP}-40,0.5 \mathrm{mM}$ ethylenediaminetetraacetic acid [EDTA]) and $50 \mu \mathrm{L}$ of RNase A $(10 \mathrm{mg} / \mathrm{mL}$ in Tris-EDTA buffer, $\mathrm{pH}$ 8.0) solution were added. The cells were incubated at room temperature for 30 minutes in the dark, and the cell cycle was analyzed by flow cytometry (Win Bryte HS cytometer [Bio-Rad], using software Win Bryte, Bio-Rad Laboratories Inc., Hercules, CA, USA). A minimum quantity of 20,000 cells per sample was collected, and the DNA histograms were further analyzed using the ModFit LT software (Verity Software House, Topsham, ME, USA) for cell cycle analysis.

\section{Transwell assay}

The chemotactic motility of HUVECs was determined using transwell migration chambers (Corning) with $6.5 \mathrm{~mm}$ diameter polycarbonate filters ( $8 \mu \mathrm{m}$ pore size), as described previously. ${ }^{28}$ In brief, the bottom chambers were filled with $750 \mathrm{~mL}$ of RPMI 1640 medium containing all supplements. HUVECs $\left(3 \times 10^{4}\right.$ cells per well) were seeded in top chambers with DMSO or various doses of BPC-157 $(1 \mu \mathrm{g} / \mathrm{mL}, 5 \mu \mathrm{g} / \mathrm{mL}$, and $10 \mu \mathrm{g} / \mathrm{mL}$ ) in $500 \mathrm{~mL}$ RPMI 1640 with $0.5 \%$ FBS. Cells were allowed to migrate for 12 hours. Nonmigrated cells were removed with cotton swabs, and migrated cells were fixed with ice-cold methanol and stained with 4',6-diamidino-2phenylindole (DAPI). Images were captured using Canon PowerShot A640 camera on Zeiss inverted microscope with $\times 100$ magnification, and invasive cells were quantified by manual counting.

\section{Wound healing assay}

Wound healing assays were performed as previously described. ${ }^{29}$ HUVECs were allowed to grow to full confluence in six-well plates. Subsequently, cells were wounded by pipette tips and washed twice with media to remove detached cells, and photomicrographs of initial wounds were taken using Canon PowerShot A640 camera (at $\times 100$ magnification). Thereafter, RPMI 1640 containing 1\% FBS was added to prevent proliferation. At the time of wounding, cells were treated with DMSO or $1 \mu \mathrm{g} / \mathrm{mL}-10 \mu \mathrm{g} / \mathrm{mL}$ dose of BPC-157. The wound area was photographed immediately after wounding ( 0 hours), and again at 12 hours postscratch using brightfield exposure at $\times 10$ magnification on a Nikon eclipse $80 \mathrm{i}$ epifluorescence microscope. The images were captured using a Canon PowerShot A640 digital camera. The distance between the edges of the wound were measured at ten different areas from the wound edge to edge using Spot software. The measurements were then converted into a percentage using the following formula: \% of wound remaining $=$ (measurement at time 12 hours/measurement at time 0 hours) $\times 100$; then the percentage of wound closure was calculated as follows: $100 \%-\%$ of wound remaining.

\section{Endothelial cell tube formation assay}

To examine the effect of BPC-157 on angiogenesis in vitro, tube formation assay was performed as described previously. ${ }^{28}$ In this assay, we used two study protocols. 
In the first protocol, growth factor-reduced matrigel was pipetted into prechilled 24 -well plates $(150 \mathrm{~mL}$ matrigel per well) and polymerized for 45 minutes at $37^{\circ} \mathrm{C}$. In the second protocol, HUVECs $\left(4 \times 10^{4}\right.$ cells per well $)$ in complete media were simultaneously seeded with DMSO or BPC-157 $(1 \mu \mathrm{g} / \mathrm{mL}, 5 \mu \mathrm{g} / \mathrm{mL}$, and $10 \mu \mathrm{g} / \mathrm{mL})$ in matrigel-coated plates. Each treatment was performed in triplicate. The enclosed networks of tubes were photographed 12 hours later using Canon PowerShot A640 camera on Zeiss inverted microscope with $\times 100$ magnification.

\section{Gene chip assay}

Total RNA was extracted from control and BPC-157 -treated cells exposed for 12 hours using an RNeasy Mini Kit (Qiagen, Valencia, CA, USA). Complementary DNA (cDNA) was made by reverse transcription of RNA (2 $\mu \mathrm{g})$ using Moloney murine leukemia virus reverse transcriptase (Promega, Madison, MI, USA) and labeled with Biotin-16-2'-deoxy-uridine-5'-triphosphate (Roche Diagnostics, Indianapolis, IN, USA). The labeled cDNAs were used to detect marker genes of signal transduction pathways on microarray membranes using Human Signal Transduction PathwayFinder ${ }^{\mathrm{TM}} \mathrm{RT}^{2}$ ProfilerTM PCR Array $^{\mathrm{TM}}$ (SuperArray System, Bioscience, Frederick, MD, USA). The membranes were prehybridized at $60^{\circ} \mathrm{C}$ for 2 hours, then hybridized at $60^{\circ} \mathrm{C}$ for 10 hours, and washed with wash solution twice for 15 minutes. The biotin-labeled cDNAs on the hybridized membranes were detected using alkaline phosphatase-conjugated streptavidin CDP-StarTM substrate. The membrane was exposed to a Kodak X-ray film, and densitometry of the spots was performed using the Fluor-S MultiImage system (Bio-Rad). Relative ratios of the spot densities between BPC-157-treated and control samples were calculated. Intensities of spots for blank and the housekeeping gene peptidylprolyl isomerase A were used for normalization of the data. Levels of marker gene expression in BPC-157-exposed and control cells were compared. After normalization, the levels of marker gene expression were determined by expressing the ratio of BPC-157-modulated genes to control genes. The genes with ratios of $>2.0$ or $<0.5$ were selected and considered to be significantly up- or downregulated, respectively.

\section{Real-time quantitative polymerase chain reaction}

Total RNA was extracted from cells using the Trizol reagent (Takara Bio Inc, Japan) according to the manufacturer's instructions. cDNA was prepared by using a reverse transcription kit from Takara Bio Inc. Real-time polymerase chain reaction (PCR) was performed by using a kit (SYBR Premix EX Taq, Takara Bio Inc.) and the ABI PRISM 7300 realtime PCR system. The primer sequences are listed in Table 1. Furthermore, $\beta$-actin was used as an internal control.

\section{Western blot}

Cells were harvested and proteins were extracted using cell lysis buffer supplemented with $0.3 \%$ phenylmethylsulfonyl fluoride and proteinase and phosphatase inhibitors. Proteins were separated by sodium dodecyl sulfate polyacrylamide gel electrophoresis and transferred to polyvinylidene difluoride membranes (Millipore, Bedford, MA, USA). After blocking in $5 \%$ skimmed milk powder for 2 hours at room temperature, the samples were incubated overnight at $4{ }^{\circ} \mathrm{C}$ with primary antibodies, including ERK1/2 (\#9102), p-ERK1/2 (\#9101), JNK1/2 (\#9252), p-JNK (\#9251), p38 MAPK (\#9212), and p-p38 MAPK (\#9211), which were obtained from Cell Signaling Technology (Beverly, MA, USA), as well as VEGF-a (sc-7269) and Tubulin (sc-8035), which were obtained from Santa Cruz Biotechnology (Santa Cruz, CA, USA). After washing three times with TBST (Tris-buffered saline supplemented with $0.1 \%$ Tween-20), the samples were incubated for 1 hour at room temperature with a secondary antibody. Bound antibodies were detected using the enhanced chemiluminescent substrate (ECL, Pierce, Rockford, IL, USA). The bands were assessed by densitometry with Image J software (National Institutes of Health).

\section{Statistical analysis}

Data were analyzed using SPSS 13.0 software and plotted as mean \pm standard deviation. Wound closure rate

Table I Primers used for real-time PCR detection of gene expression

\begin{tabular}{llll}
\hline Gene & GenBank accession no & Forward primers & Reverse primers \\
\hline FOS & NM_005252 & TACACTCCAAGCGGAGACAG & TCCTTCTCCTTCAGCAGGTT \\
JUN & NM_002228 & GGTGGCACAGCTTAAACAGA & AACTGCTGCGTTAGCATGAG \\
EGR-I & NM_001964 & TTCGGATCCTTTCCTCACTC & GTTGCTCAGCAGCATCATCT \\
VEGF-a & NM_001287107 & TGCACCCACGACAGAAGGA & GGCAGTAGCTTCGCTGGTAGAC \\
$\beta$-actin & NM_001101.3 & GCGTGACATTAAGGAGAAG & GAAGGAAGGCTGGAAGAG \\
\hline
\end{tabular}

Abbreviations: EGR, early growth response; PCR, polymerase chain reaction; VEGF, vascular endothelial growth factor. 
was evaluated by single-factor repeated measurement. Statistically significant differences were analyzed by one-way analysis of variance. $P<0.05$ was considered statistically significant.

\section{Results}

\section{BPC-I57 accelerates wound closure in alkali-burned rats}

During the study, no abnormalities were observed in the general condition and behavior of rats in all treatment cohorts, including asitia, nausea, diarrhea, cough, or weight loss, and no symptoms of allergic response such as hydroposia or localized rash occurred in animals receiving bFGF or BPC-157. The final autopsy did not show any pathological changes in various organs. bFGF, which is one of the 22 different isotypes of FGF, plays a crucial role in the wound healing process by promoting fibroblast proliferation, inducing neovascularization, and increasing the synthesis of collagenase..$^{30-33}$ As the topical administration of human recombinant $\mathrm{bFGF}$ has been shown to be effective for wound healing in clinical situations, we selected bFGF as a positive reagent in this study. Wound repair evaluation proved that rats treated with either bFGF or BPC-157 showed a significantly faster wound closure than those left untreated (Figure 1 and Table 2): BPC-157 (800 ng/mL) group with $14.13 \% \pm 4.91 \%$ versus $10.80 \% \pm 4.84 \%$ for bFGF group versus $5.42 \% \pm 2.09 \%$ for model control at day 4 . The acceleration of wound healing by BPC-157 $(800 \mathrm{ng} / \mathrm{mL})$ became remarkably significant on days 12 and 16, showing an average healing of $54.38 \% \pm 11.37 \%$ and $77.53 \% \pm 10.25 \%$, respectively. Similar to the bFGF-treated group, on the 18th day postwounding, the BPC-157-treated group showed nearly $80 \%$ wound closure, whereas rats left untreated recovered by $60 \%$ at most.

Histological examination of skin sections with HE and Masson staining presented insights into the morphology of
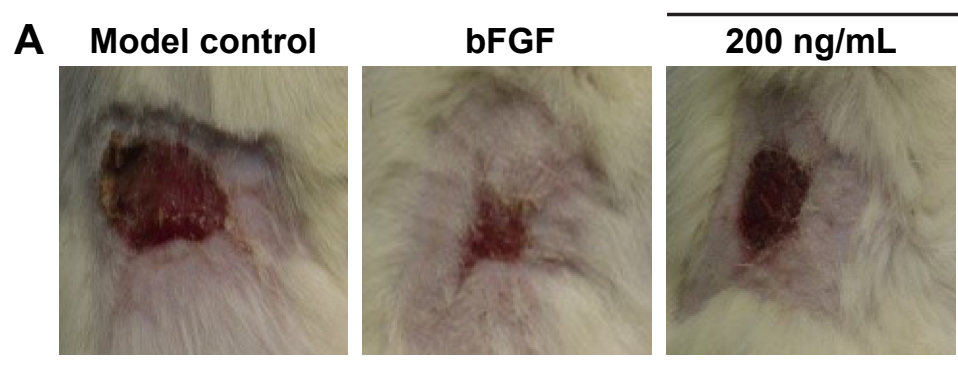

BPC-157

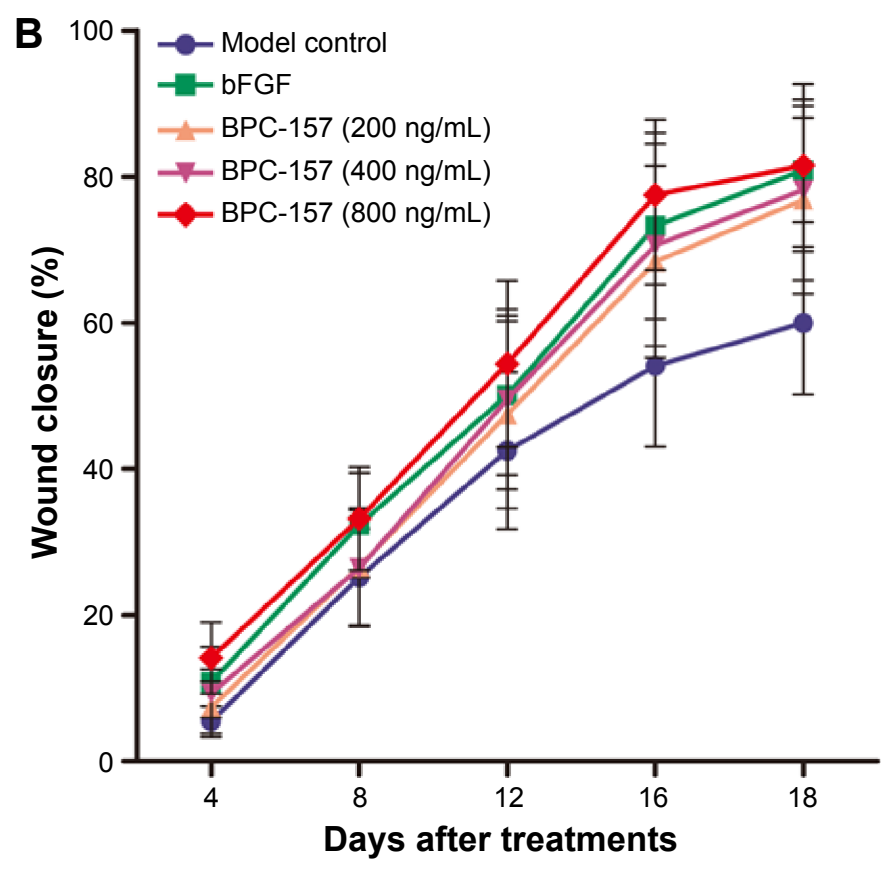

Figure I Efficacy of BPC-I57 in murine wound healing compared to that of bFGF.

Notes: (A) Representative images of wounds on the 18th day in the five tested groups: untreated rats, bFGF-treated rats, and rats treated with different concentrations of BPC- $157(200 \mathrm{ng} / \mathrm{mL}, 400 \mathrm{ng} / \mathrm{mL}$, and $800 \mathrm{ng} / \mathrm{mL})$. (B) Wound area at every 4 days postwounding $(\mathrm{n}=10)$. The bars represent standard error of the mean wound closure. Abbreviations: BPC-157, body protective compound I57; bFGF, basic fibroblast growth factor. 
Table 2 Wound closure percentage in rat skin with alkali burn during 18 days' treatment with bFGF or BPC-I57

\begin{tabular}{|c|c|c|c|c|c|}
\hline \multirow[t]{2}{*}{ Cohorts $(n=10)$} & \multicolumn{5}{|l|}{ Days } \\
\hline & 4 & 8 & 12 & 16 & 18 \\
\hline Model control & $5.42 \pm 2.09$ & $25.20 \pm 6.66$ & $42.51 \pm 10.70$ & $54.14 \pm 11.09$ & $60.00 \pm 9.82$ \\
\hline bFGF (200 ng/mL) & $10.80 \pm 4.84$ & $32.32 \pm 7.11$ & $50.10 \pm 10.92$ & $73.30 \pm 12.73$ ** & $80.93 \pm 7.11 * *$ \\
\hline BPC-I $57(200 \mathrm{ng} / \mathrm{mL})$ & $7.34 \pm 3.55$ & $26.66 \pm 8.0 \mathrm{I}$ & $47.44 \pm 12.84$ & $68.37 \pm 13.12 * *$ & $76.85 \pm 12.86 * *$ \\
\hline BPC-I57 (400 ng/mL) & $9.29 \pm 3.34$ & $26.40 \pm 7.99$ & $49.52 \pm 12.33$ & $70.65 \pm 13.82 * *$ & $78.18 \pm 14.38 * *$ \\
\hline BPC-I $57(800 \mathrm{ng} / \mathrm{mL})$ & $|4.13 \pm 4.9|$ & $33.20 \pm 7.03$ & $54.38 \pm 11.37$ & $77.53 \pm 10.25^{* *}$ & $81.55 \pm 11.14^{* *}$ \\
\hline
\end{tabular}

Notes: Data are presented as mean \pm standard deviation and were analyzed by Student's $t$-test. $* * P<0.01$ versus model control.

Abbreviations: BPC-157, body protective compound I57; bFGF, basic fibroblast growth factor.

skin layers and collagen extent during the healing process (Figure 2). Compared with model control, BPC-157-treated groups showed a significant healing response similar to that of the bFGF-treated group. In the model control group, the granulation tissues formed were hypocellular and covered by a thin immature epithelium. It was clearly visible that the epidermal and subepidermal layers were well organized in the BPC-157- and bFGF-treated groups. In addition, the BPC157- and bFGF-treated groups showed better granulation tissue formation, reepithelialization, and dermal remodeling,

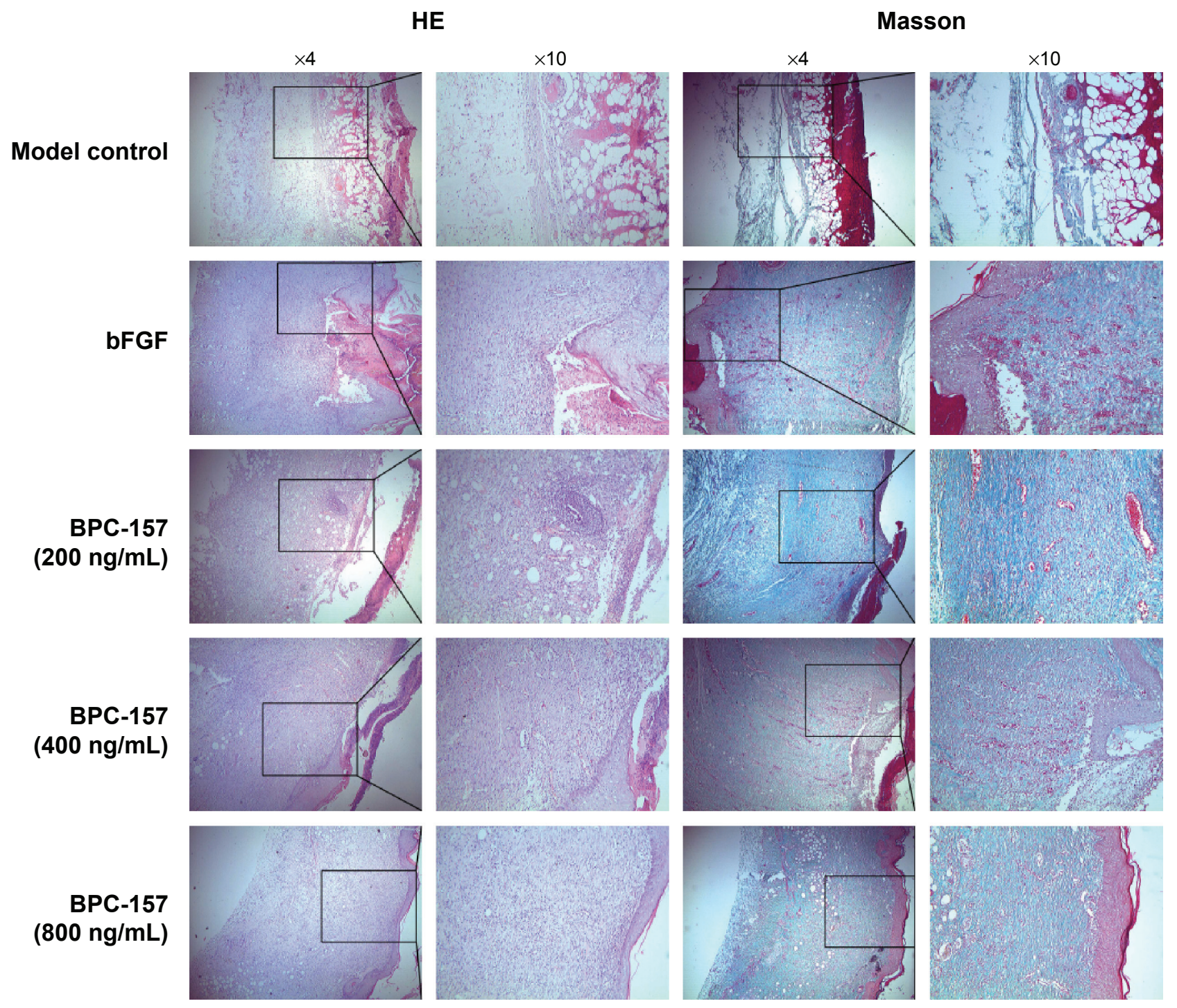

Figure 2 BPC-I57 increased wound reepithelialization and collagen content of granulation tissue.

Notes: Wound sections were stained with (left) HE and (right) Masson's trichrome (Masson). Representative images of sections are presented for all five groups. Abbreviations: BPC-157, body protective compound I57; bFGF, basic fibroblast growth factor; HE, hematoxylin-eosin staining. 
when compared to the model control group, on the 18th day post wounding. Using Masson staining, we found that the extent of collagen deposition was significantly higher in BPC-157- and bFGF-treated groups. Moreover, the results showed that both BPC-157 and bFGF could promote VEGF expression in wounded skin tissues (Figure 3A-B).

All of these data demonstrate that BPC-157 is effective in the very low dose range and that it accelerates wound healing, which resembles previous conclusions about BPC- 157 . At the same time, these data also suggest that the effect of BPC-157 on alkali-burn wound repair is, apparently, comparable with that of bFGF.

\section{BPC-I57 enhances cell proliferation of endothelial cells}

The established view in cellular biology dictates that fibroblasts, keratinocytes, and endothelial cells contribute to the proliferation course of wound healing. Therefore, we assessed the influence of BPC-157 on cell growth of NIH3T3, $\mathrm{HaCaT}$, and HUVEC lines by a MTT cell proliferation assay. As shown in Figure 4A, BPC-157 (1 $\mu \mathrm{g} / \mathrm{mL}-10 \mu \mathrm{g} / \mathrm{mL})$ was found to significantly increase the proliferation of HUVECs in a concentration-dependent manner after 48 hours of treatment. However, BPC-157 did not promote either NIH3T3 or HaCaT cell proliferation (data not shown). We next investigated the effect of BPC-157 on the HUVEC cell cycle distribution. HUVECs were exposed to BPC-157 ( $1 \mu \mathrm{g} / \mathrm{mL}, 5 \mu \mathrm{g} / \mathrm{mL}$, and $10 \mu \mathrm{g} / \mathrm{mL}$ ) for 48 hours and then analyzed by flow cytometry. Results showed that BPC-157 apparently reduced the cell number in the G0/G1 phase in a dose-dependent manner compared with the number in the control group (Figure 4B). These findings indicated that BPC-157 might modulate the cell viability and affect HUVEC cell cycle exit in the G0/G1 phase.

\section{BPC-I57 promotes cell migration and tube formation in endothelial cells}

The effect of BPC-157 on the migration of endothelial cells was evaluated using a modified Boyden chamber assay (Figure 5A). In DMSO-treated control, only few endothelial cells migrated from the upper to the lower chamber through the membrane after 12-hour incubation, when the lower chamber contained culture medium supplemented with $10 \%$ FBS as a chemoattractant. As shown in Figure 5B, BPC-157 promoted the migration of HUVECs in a concentrationdependent manner. The effect of BPC-157 on cell motility was also evaluated by the scratch wound assay (Figure 5C). Treatment of HUVECs with BPC-157 $(1 \mu \mathrm{g} / \mathrm{mL}, 5 \mu \mathrm{g} / \mathrm{mL}$, and $10 \mu \mathrm{g} / \mathrm{mL}$ ) enhanced cell motility in a concentrationdependent manner compared with untreated cells. The open wound areas in BPC-157-treated wells were significantly smaller than those of untreated wells $(P<0.05)$ (Figure 5D).

Because BPC-157 stimulated endothelial cell migration, we next examined its effect on tube formation by HUVECs. Endothelial cells seeded on a three-dimensional matrix, such as Matrigel, are able to form capillary-like structure. ${ }^{34}$ HUVECs plated on Matrigel in limiting medium with increasing concentrations of BPC-157 formed more extensive tubes in a dose-dependent manner (Figure 5E-F). Addition of $5 \mu \mathrm{g} / \mathrm{mL}$ BPC-157 stimulated a morphological change in HUVECs without significantly increasing the tube network formation, whereby increasing the dose to $10 \mu \mathrm{g} / \mathrm{mL}$ caused greater tube formation compared to control.
A

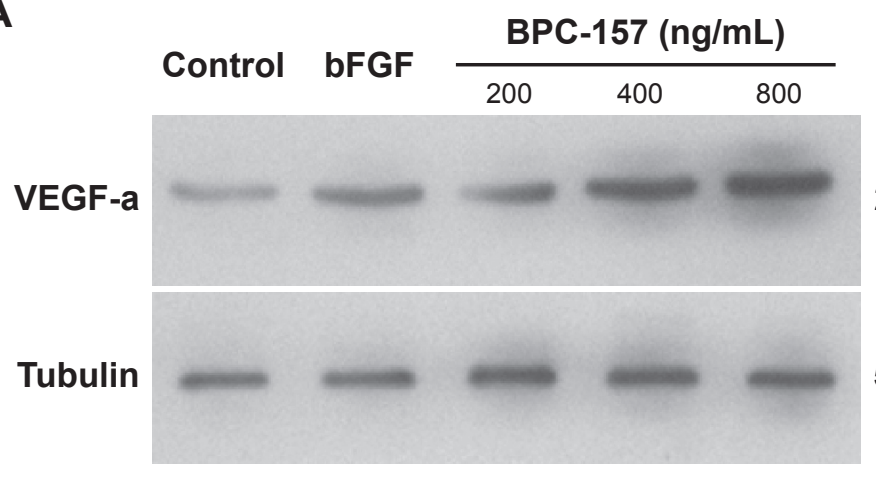

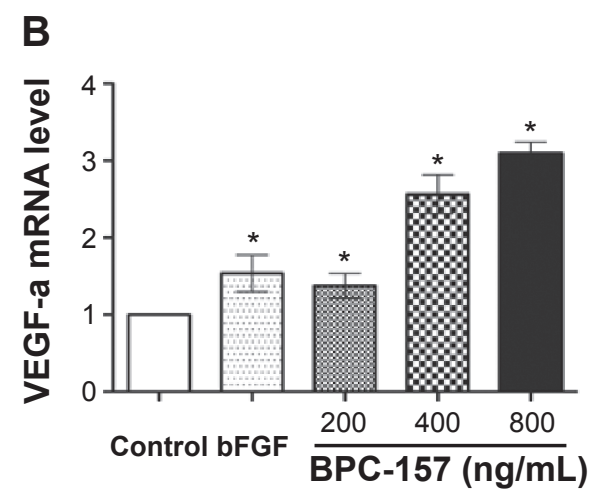

Figure 3 BPC-157 promoted the expression of VEGF-a in wounded skin tissues.

Notes: (A) Western blot analysis of the effect of BPC-I57 on VEGF-a protein expression. (B) Real-time PCR was used to test the effect of BPC-I57 on VEGF-a mRNA expression. Data are presented as mean \pm SD. Differences between the treated and untreated control groups were determined by Student's unpaired $t$-test. $* P<0.05$ significantly different from the control group.

Abbreviations: bFGF, basic fibroblast growth factor; BPC-I57, body protective compound I57; PCR, polymerase chain reaction; SD, standard deviation; VEGF, vascular endothelial growth factor. 
A

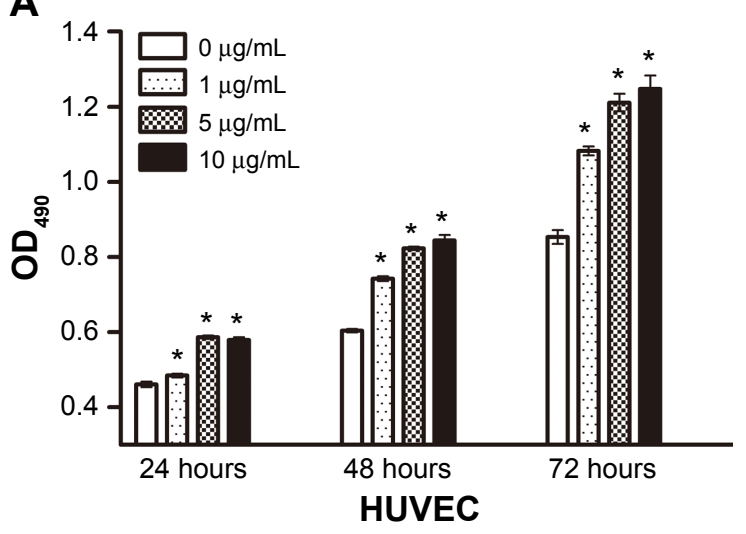

B

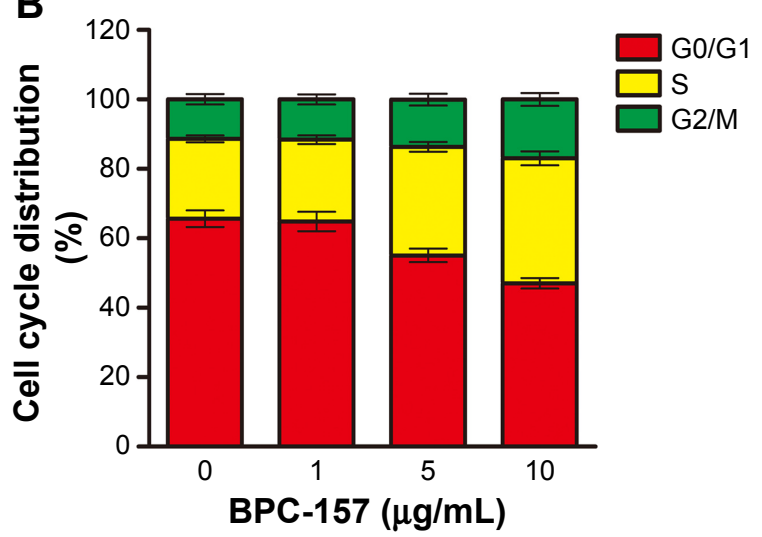

Figure 4 BPC-I57 influences the proliferation and cell cycle distribution of HUVECs.

Notes: (A) Cells were treated with or without I $\mu \mathrm{g} / \mathrm{mL}, 5 \mu \mathrm{g} / \mathrm{mL}$, or $10 \mu \mathrm{g} / \mathrm{mL}$ BPC-I57 for 24 hours to 72 hours, and cell proliferation viability was determined by the MTT assay. Results are showed as absorbance at $490 \mathrm{~nm}$ values in treated and untreated control cells. (B) PI staining was used to analyze the cell cycle distribution. Percentages of BPC-I57-treated and untreated cells that were in the G0/GI, S, and G2/M phases are shown. Data are presented as mean \pm SD. $* P<0.05$ significantly different from the control group.

Abbreviations: BPC-157, body protective compound I57; HUVECs, human umbilical vein endothelial cells; MTT, 3-(4,5-dimethylthiazol-2-yl)-2,5-diphenyltetrazolium bromide; PI, propidium iodide; SD, standard deviation; OD, optical density.

\section{Gene expression analysis}

To obtain further insight into the mechanisms of BPC-157 participation in cell signal transduction, we carried out a quantitative real-time PCR using a Signal Transduction PathwayFinder ${ }^{\mathrm{TM}} \mathrm{RT}^{2}{ }^{2}$ Profiler ${ }^{\mathrm{TM}}$ PCR Array, which contained a set of primers for 84 key genes representative of 18 different signal transduction pathways. Across the panel of 84 mRNAs screened in the array, eight were induced or repressed two folds or more in the samples of BPC-157 treatment compared with that of controls. The transcription of c-Fos, c-Jun, and Egr-1 in the mitogenic pathway was upregulated by 4.99 , 7.05 , and 3.70 folds, respectively. The transcription of Sele in the low-density lipoprotein pathway was upregulated by 4.00 folds, while Wisp in the Wnt pathway was upregulated by 2.21 folds. The transcriptional profiles of Bmp 4 in the Hedgehog pathway showed downregulation by -4.53 folds, with Lep in the Insulin pathway being downregulated by -5.26 folds. The transcription of Vcam 1 in the NF- $\mathrm{\kappa B}$ pathway was also downregulated by -5.34 folds (Table $3, P<0.05$ ).

\section{BPC-I 57 promotes the activation of ERKI/2 in endothelial cells}

To evaluate the effect of BPC-157 on intracellular signal transduction, the phosphorylation levels of ERK1/2, JNK, and p38 mitogen-activated protein kinase (MAPK) were examined in HUVECs. Results showed that BPC-157 had a dosage-dependent effect on the phosphorylation of ERK1/2 in HUVECs (Figure 6). However, no significant change in p-JNK protein level was observed in HUVECs (Figure 6).
In addition, the increase in the phosphorylation of p38 MAPK was not statistically significant (Figure 6).

\section{Involvement of ERKI/2 pathway in BPC- I57-induced cell proliferation, migration, and tube formation}

To explore whether the ERK1/2, JNK, or p38 pathway was involved in BPC-157-induced cell proliferation, migration, and tube formation, PD98059 (ERK1/2 inhibitor), SP600125 (JNK inhibitor), and SB203580 (p38 inhibitor) were used. As shown in Figure 7A, pretreatment with $10 \mu \mathrm{M}$ PD98059 obviously inhibited BPC-157-induced proliferation of HUVECs, as detected by the MTT assay $(P<0.05)$, while pretreatment with $10 \mu \mathrm{M} \mathrm{SP} 600125$ and $10 \mu \mathrm{M}$ SB203580 had no effect on proliferation. The number of migrated cells remarkably decreased when ERK1/2 signal pathways were blocked by its inhibitor PD98059 (Figure 7B-C). On the other side, the number of migrated cells decreased when the JNK $1 / 2$ and 338 MAPK signal pathways were blocked by their inhibitors SP600125 and SB203580, respectively, but no significant decline was noted. Additionally, a similar trend was observed in cell migration using the wound healing assay (Figure 7D-E). Moreover, we tested whether the angiogenic effect of BPC157 was mediated via MAPKs. Matrigel tube formation was studied using cells pretreated with specific MAPK inhibitors. As shown in Figure 7F-G, BPC-157-induced tube formation was significantly inhibited by PD98059, but not by SP600125 and SB203580. 
A
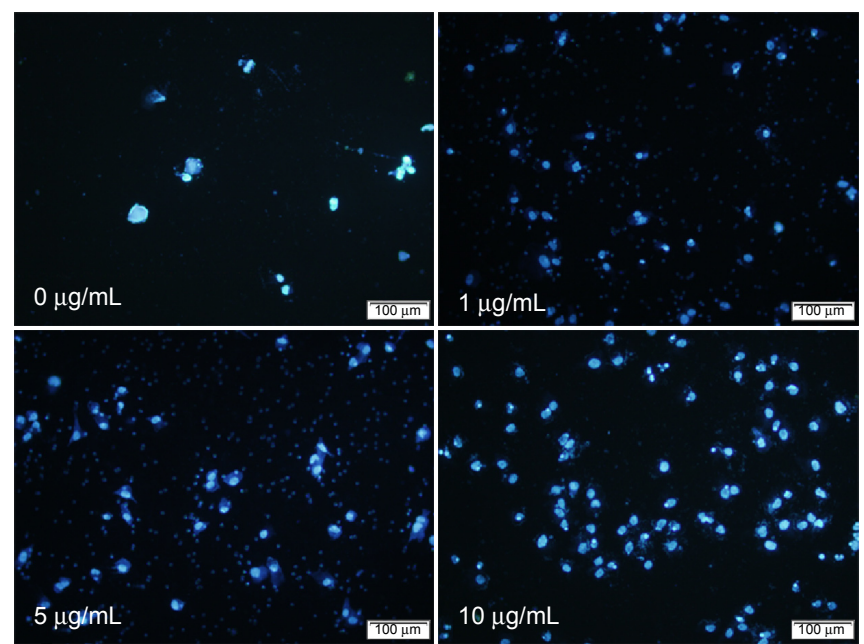

\section{C}

12 hours

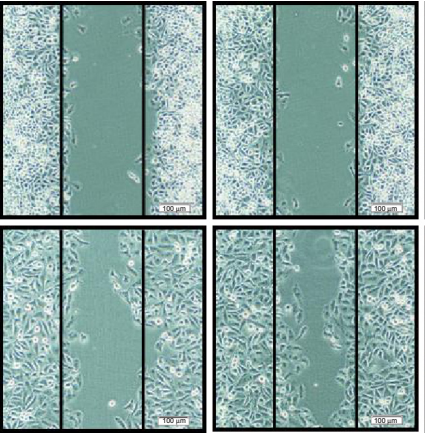

$0 \mu \mathrm{g} / \mathrm{mL}$

$1 \mu \mathrm{g} / \mathrm{mL}$

\begin{abstract}
$5 \mu \mathrm{g} / \mathrm{mL}$
\end{abstract}
$10 \mu \mathrm{g} / \mathrm{mL}$

E

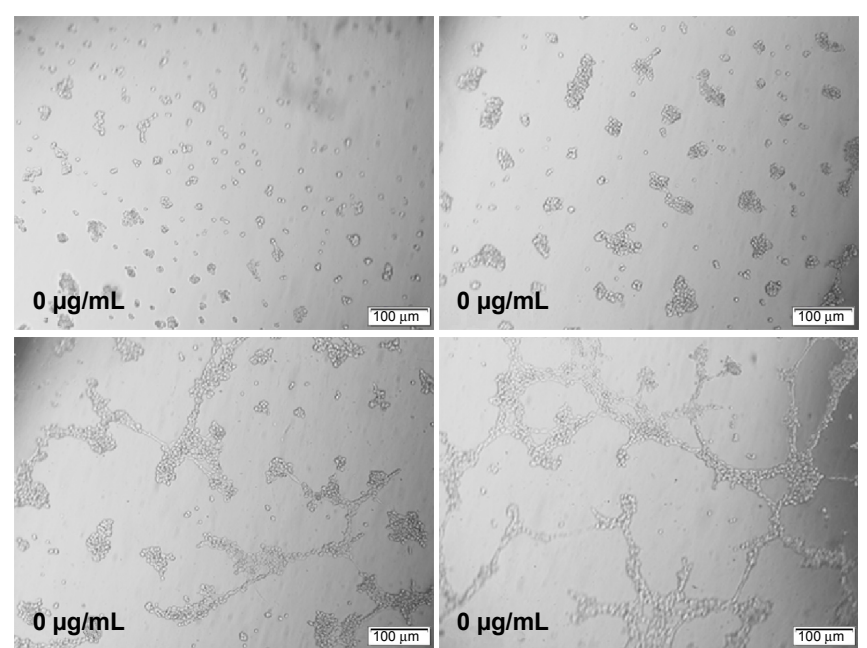

B

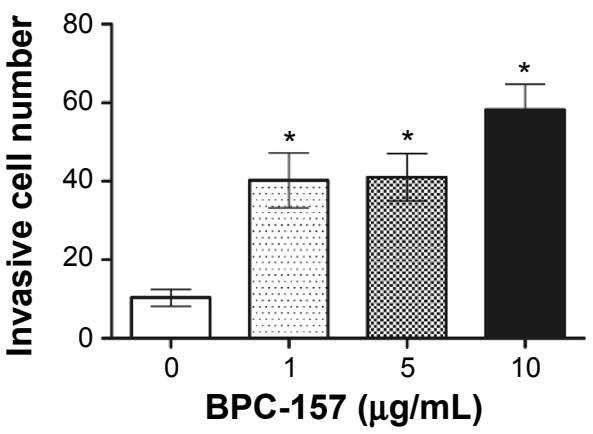

D

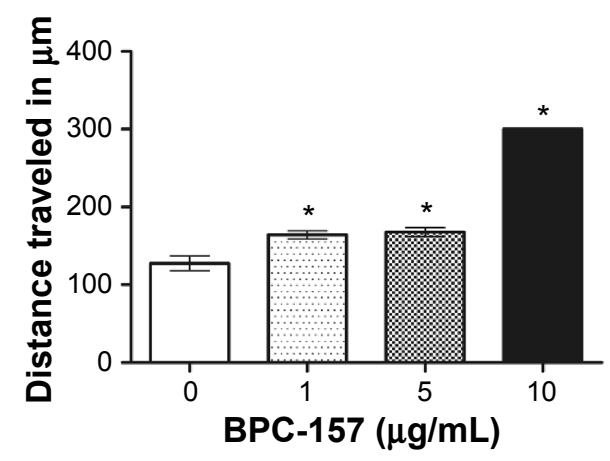

F

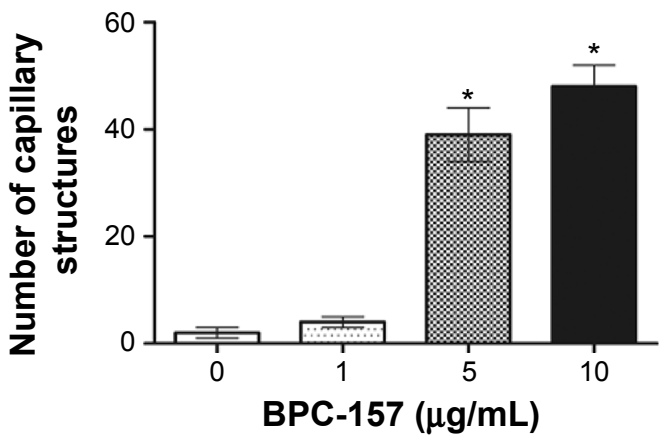

Figure 5 Effect of BPC-I57 on cell migration and tube formation of HUVECs.

Notes: (A) Representative photomicrographs showing the stained cells on the lower side of membranes. The cells in the upper chambers were treated with DMSO (control, $0 \mu \mathrm{g} / \mathrm{mL}$ ) or I $\mu \mathrm{g} / \mathrm{mL}, 5 \mu \mathrm{g} / \mathrm{mL}$, and $10 \mu \mathrm{g} / \mathrm{mL}$ BPC-157. After 12 hours of incubation, those cells which had migrated to the lower chambers were stained and the numbers were counted. (B) Quantification of cell migration in HUVECs is shown. (C) A scratch wound was created using a $20 \mu \mathrm{L}$ sterile serological pipette in a confluent HUVEC culture after incubation with BPC-157. The images were taken at 0 hours and 12 hours. The black lines show the area where the scratch wound was created. (D) Quantification of cell motility in HUVECs is shown. (E) Effect of BPC-157 on tube formation in HUVECs. Photomicrographs represent the matrigel tube formation of HUVECs after 8 hours' incubation. (F) Quantification of capillary structure in HUVECs is shown. Data are presented as mean \pm SD. Differences between the treated and untreated control groups were determined by Student's unpaired $t$-test. ${ }^{*} P<0.05$ significantly different from the control group.

Abbreviations: BPC-157, body protective compound I57; DMSO, dimethyl sulfoxide; HUVECs, human umbilical vein endothelial cells; SD, standard deviation. 
Table 3 List of genes differentially expressed in HUVECs after BPC-I57 (I0 $\mu \mathrm{g} / \mathrm{mL})$ stimulation, determined using the Signal Transduction PathwayFinder ${ }^{\mathrm{TM}} \mathrm{RT}^{2}$ Profiler ${ }^{\mathrm{TM}}$ PCR Array (>2-fold change)

\begin{tabular}{lllll}
\hline $\begin{array}{l}\text { GenBank } \\
\text { accession number }\end{array}$ & Gene name & Description & $\begin{array}{l}\text { Folds up- or } \\
\text { down regulation }\end{array}$ \\
\hline NM_005252 & FOS & FBJ murine osteosarcoma viral oncogene homolog & 4.99 & $\begin{array}{c}\text { P-value } \\
\text { NM_002228 }\end{array}$ \\
NM_001964 & JUN & Jun proto-oncogene & 7.05 & 0.007 \\
NM_000450 & SELE & Early growth response I & 3.70 & 0.024 \\
NM_003882 & WISPI & Selectin E & 4.00 & 0.043 \\
NM_13085I & WMP4 & BNTI-inducible signaling pathway protein I & 2.21 & 0.015 \\
NM_000230 & LEP & Leptin & -4.53 & 0.008 \\
NM_001078 & VCAMI & Vascular cell adhesion molecule I & -5.26 & 0.010 \\
\hline
\end{tabular}

Abbreviations: BPC-157, body protective compound I57; HUVECs, human umbilical vein endothelial cells; PCR, polymerase chain reaction.

Taken together, these results have demonstrated that BPC-157 induces proliferation, migration, and tube formation of endothelial cells, wherein the ERK1/2 signaling pathway plays a promoting role.

\section{Discussion}

As one of the most complex biological processes that occur during human life, the wound repair process involves four steps that include inflammation around the site of injury, angiogenesis and the development of granulation tissue, repair of the connective tissue and epithelium, and ultimately remodeling that leads to a healed wound. ${ }^{1}$ The clinical treatment of skin loss due to severe and massive burns or wounds continues to be a major problem in surgical procedures. A therapeutic agent selected for the treatment of wounds should ideally improve one or more phases of healing without

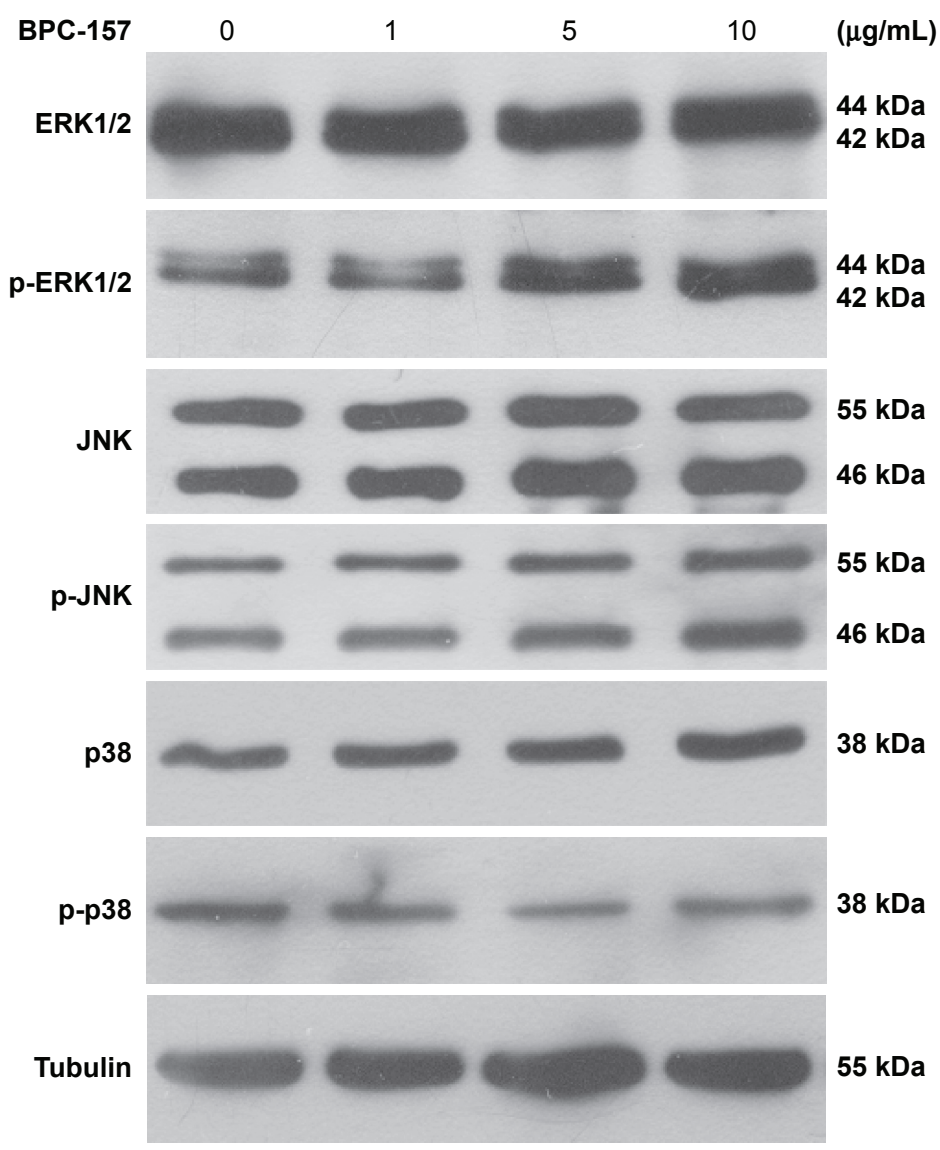

Figure 6 Western blot analysis of the effect of BPC-157 on the ERKI/2, JNK, and p38 phosphorylation levels.

Notes: HUVECs were synchronized in medium for 24 hours and then treated with or without I $\mu \mathrm{g} / \mathrm{mL}, 5 \mu \mathrm{g} / \mathrm{mL}$, or $10 \mu \mathrm{g} / \mathrm{mL}$ BPC-I57 for another I hour. Immunoblotting was performed three to four times using independently prepared cell lysates, and protein levels for p-ERKI/2, total ERK, p-JNK, total JNK, p-p38, total p38, and tubulin in every group and their corresponding relative densities are shown.

Abbreviations: BPC-I57, body protective compound I57; ERKI/2, extracellular signal-regulated kinases I and 2; HUVECs, human umbilical vein endothelial cells. 

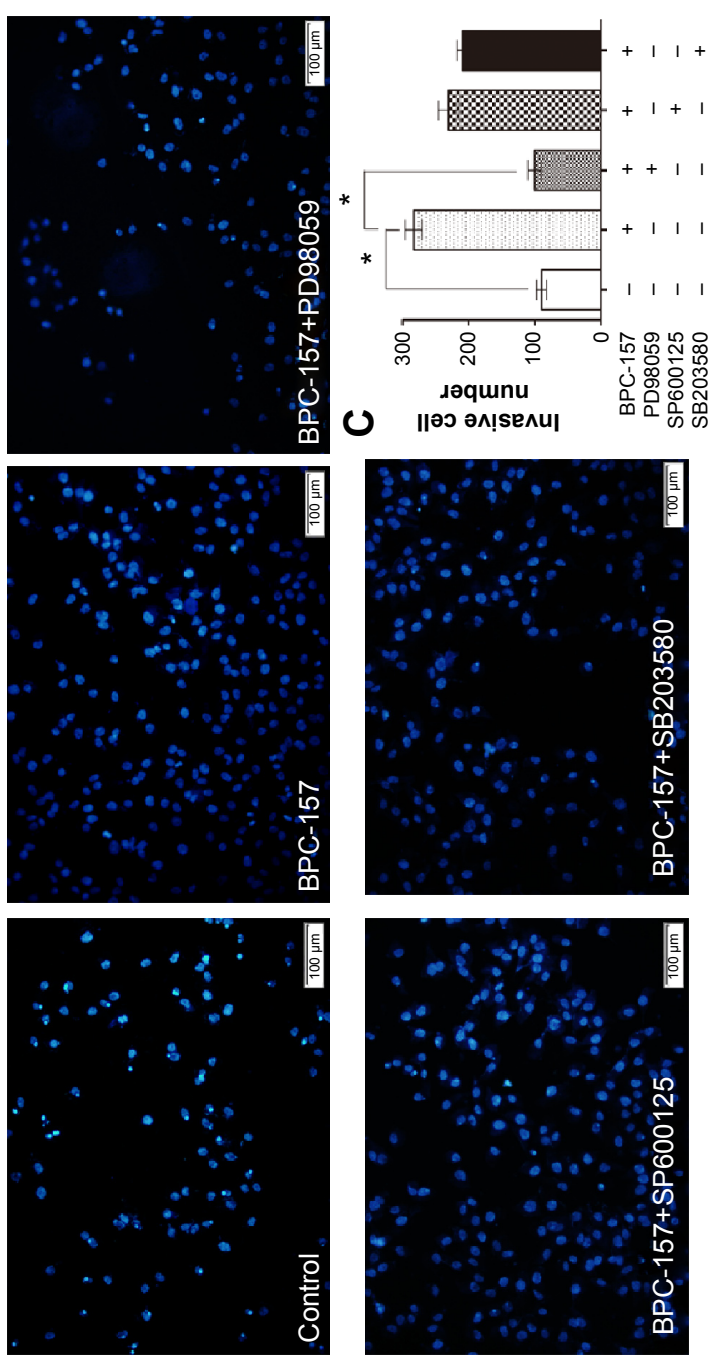

m
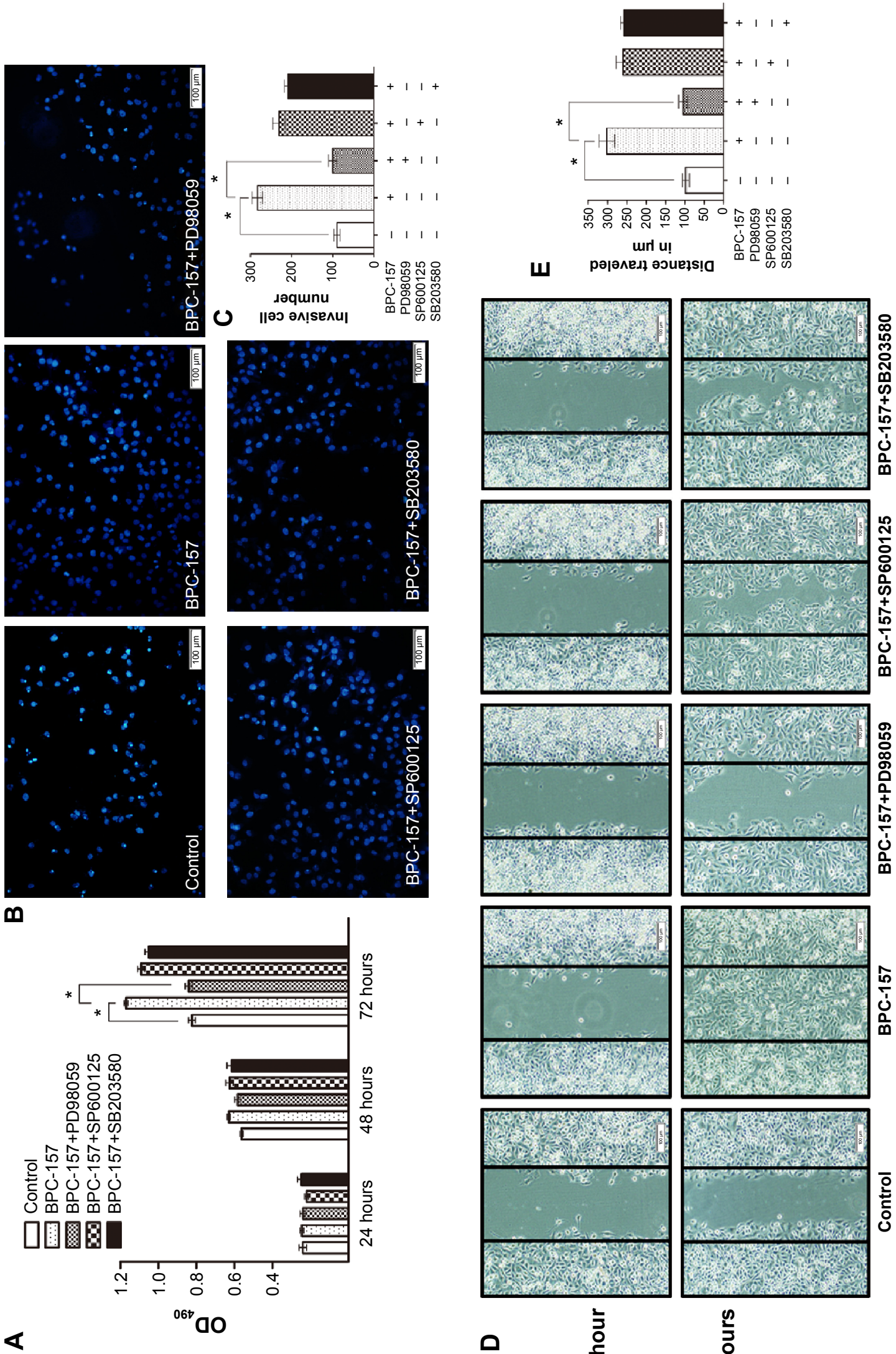

0

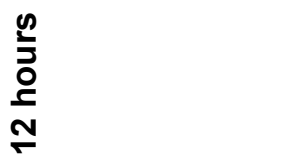

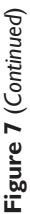




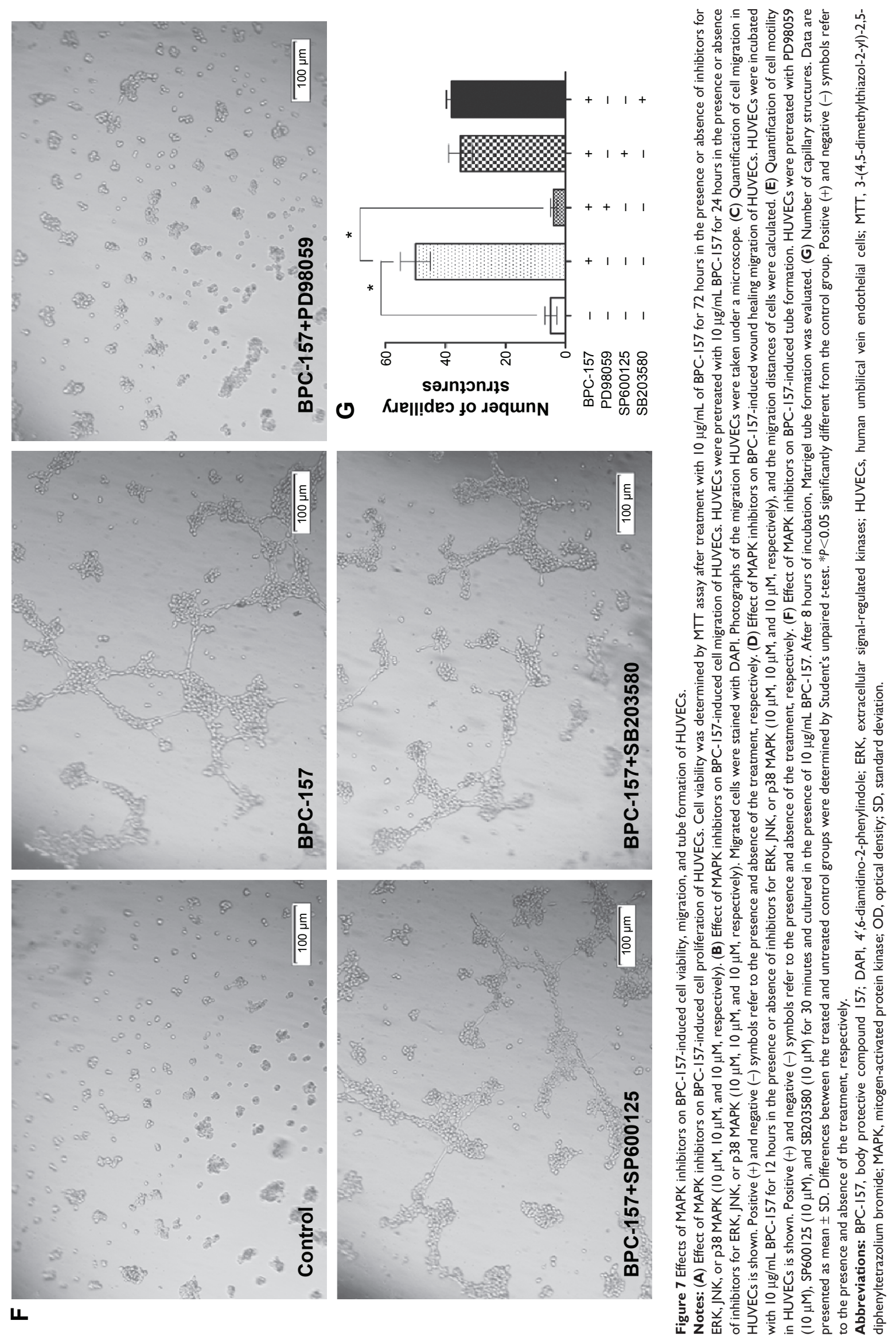


producing deleterious side effects. A previous study ${ }^{35}$ has demonstrated that BPC-157 cream improves healing of burn wounds caused by exposure to direct flame. Herein, we explored the role of topical treatment with BPC-157 on alkali-induced burn wound healing in rats. The present study shows a significant improvement in alkali-induced burn wound healing in the rats treated with BPC- 157 .

In this study, we found that BPC-157 is effective in the very low dose range and accelerates wound healing and that the wound repair process, which involves steps that include inflammation, collagen deposition, angiogenesis, development of granulation tissue, and the repair of epithelium, in bFGF- or BPC-157-treated groups was better than that in the model control group. These data also suggest that the effect of BPC-157 on alkali-burn wound repair is, apparently, comparable with that of bFGF. More interestingly, BPC157 is highly stable and resistant to hydrolysis or enzyme digestion, even in the gastric juice. Furthermore, it is easily dissolved in water and needs no carrier for its application. ${ }^{13}$ These findings indicate that BPC-157 may become a therapeutic agent for the treatment of chemical-induced burn wound. Previous studies have demonstrated that BPC-157 promotes the healing of different tissues, including skin, ${ }^{36}$ muscle, ${ }^{15,37-39}$ bone, ${ }^{40}$ ligament, ${ }^{41}$ and tendon ${ }^{42}$ in various animal models. However, the underlying mechanism has not been fully elucidated.

The theory of cell biology in wound healing emphasized that endothelial cells, fibroblasts, and keratinocytes may contribute to the proliferation stage in the wound healing process. We hypothesized that BPC-157 could present some bioactivities on cells in vitro. To confirm the hypothesis, the MTT assay and cell cycle distribution were used to evaluate the effect of BPC-157 on cell proliferation. Previous studies have found that BPC-157 did not exert a direct effect in terms of accelerating the cell proliferation of cultured tendon fibroblasts, ${ }^{42}$ but our results suggested that BPC-157 modulates the cell viability and affects HUVEC cell cycle exit in G0/G1 phase. In contrast, BPC-157 did not promote either NIH3T3 or HaCaT cell proliferation.

Wound healing involves a multistep process, including cell proliferation, migration, tube formation, and remodeling. Promotion at any step may result in accelerating wound healing. Assays of endothelial cell migration showed that BPC-157 enhanced the chemotactic response of endothelial cells. In another migration/scratch wound assay, BPC-157 significantly increased the open wound area, suggesting that the motility of endothelial cells across wounds was improved. The accelerating effect in migration is consistent with a previous study that was conducted in tendon fibroblasts. ${ }^{42}$ Moreover, we did observe the promotion of tube formation in HUVECs by BPC-157.

To further investigate the mechanisms through which BPC-157 may exert its enhancement effects on proliferation, migration, and tube formation of endothelial cells, a Signal Transduction PathwayFinder ${ }^{\mathrm{TM}} \mathrm{RT}^{2}$ Profiler ${ }^{\text {TM }}$ PCR Array was used. After BPC-157 treatment, the transcriptional rates of FOS, JUN, and EGR-1 in mitogenic pathway were upregulated by $4.99,7.05$, and 3.70 folds, respectively. Therefore, we hypothesized that BPC-157 is involved in the activation of MAPK signal pathway. To evaluate the effect of BPC-157 on intracellular signal transduction, the phosphorylation level of ERK1/2, JNK, and p38 MAPK were examined in HUVECs. We demonstrated that the phosphorylation level of ERK $1 / 2$ could be modulated by BPC- 157 . However, no significant change of p-JNK and p-p38 protein level was observed in BPC-157-treated HUVECs.

Furthermore, to explore whether ERK1/2, JNK, or p38 pathway is involved in BPC-157-induced cell function, effects of the inhibitors of ERK1/2, JNK, and p38 on the proliferation, migration, and tube formation of HUVECs following BPC-157 stimulation were studied. The results indicated that pretreatment with $10 \mu \mathrm{M}$ ERK1/2 inhibitor obviously antagonized, while pretreatment with 10 $\mu \mathrm{M} J \mathrm{NK}$ inhibitor and $10 \mu \mathrm{M}$ p38 inhibitor had no effect on, BPC-157-induced proliferation, migration, and tube formation.

In conclusion, administration of BPC-157 to alkali-burn wound healing was investigated in the current study. We demonstrated that BPC-157 significantly improved the wound healing activity on alkali-burned rats. BPC-157 may exert wound healing activity by upregulating the expression of VEGF. The effects of BPC-157 on HUVECs might be mediated by activation of ERK1/2 phosphorylation, leading to enhanced cell proliferation, migration, and tube formation. These findings may provide support for the potential use of BPC-157 as a wound-healing therapeutic agent.

\section{Acknowledgment}

The work in this study was supported by the Natural Science Foundation of China (grants 30971188, 81273279, 81302560, and 81373201).

\section{Disclosure}

The authors report no conflicts of interest in this work. 


\section{References}

1. Gurtner GC, Werner S, Barrandon Y, Longaker MT. Wound repair and regeneration. Nature. 2008;453:314-321.

2. Rolfe KJ, Richardson J, Vigor C, Irvine LM, Grobbelaar AO, Linge C. A role for TGF-beta1-induced cellular responses during wound healing of the non-scarring early human fetus? J Invest Dermatol. 2007; 127:2656-2667.

3. Steed DL. Clinical evaluation of recombinant human platelet-derived growth factor for the treatment of lower extremity ulcers. Plast Reconstr Surg. 2006;117:143S-149S; discussion 50S-51S.

4. Wang L, Wu X, Shi T, Lu L. Epidermal growth factor (EGF)-induced corneal epithelial wound healing through nuclear factor kappaB subtype-regulated CCCTC binding factor (CTCF) activation. J Biol Chem. 2013;288:24363-24371.

5. Plichta JK, Radek KA. Sugar-coating wound repair: a review of FGF-10 and dermatan sulfate in wound healing and their potential application in burn wounds. J Burn Care Res. 2012;33:299-310.

6. Hara Y, Matsuura T, Tsukamoto M, Ishizaka S, Saishin M. Effect of tetra-peptide isolated from interleukin 1 (IL-1) on corneal epithelial wound healing in the rabbit. Exp Eye Res. 2001;72:107-113.

7. Saika S. Yin and yang in cytokine regulation of corneal wound healing: roles of TNF-alpha. Cornea. 2007;26:S70-S74.

8. Kim YS, Lew DH, Tark KC, Rah DK, Hong JP. Effect of recombinant human epidermal growth factor against cutaneous scar formation in murine full-thickness wound healing. J Korean Med Sci. 2010;25:589-596.

9. Wang XJ, Han G, Owens P, Siddiqui Y, Li AG. Role of TGF betamediated inflammation in cutaneous wound healing. J Investig Dermatol Symp Proc. 2006;11:112-117.

10. Ilic S, Drmic D, Franjic S, et al. Pentadecapeptide BPC 157 and its effects on a NSAID toxicity model: diclofenac-induced gastrointestinal, liver, and encephalopathy lesions. Life Sci. 2011;88:535-542.

11. Stancic-Rokotov D, Slobodnjak Z, Aralica J, et al. Lung lesions and anti-ulcer agents beneficial effect: anti-ulcer agents pentadecapeptide BPC 157, ranitidine, omeprazole and atropine ameliorate lung lesion in rats. J Physiol Paris. 2001;95:303-308.

12. Klicek R, Kolenc D, Suran J, et al. Stable gastric pentadecapeptide BPC 157 heals cysteamine-colitis and colon-colon-anastomosis and counteracts cuprizone brain injuries and motor disability. J Physiol Pharmacol. 2013;64:597-612.

13. Sikiric P, Seiwerth $S$, Rucman R, et al. Stable gastric pentadecapeptide BPC 157: novel therapy in gastrointestinal tract. Curr Pharm Des. 2011; 17:1612-1632.

14. Sikiric P, Separovic J, Buljat G, et al. The antidepressant effect of an antiulcer pentadecapeptide BPC 157 in Porsolt's test and chronic unpredictable stress in rats. A comparison with antidepressants. $J$ Physiol Paris. 2000;94:99-104.

15. Brcic L, Brcic I, Staresinic M, Novinscak T, Sikiric P, Seiwerth S. Modulatory effect of gastric pentadecapeptide BPC 157 on angiogenesis in muscle and tendon healing. J Physiol Pharmacol. 2009;60(suppl 7): 191-196.

16. Sikiric P, Marovic A, Matoz W, et al. A behavioural study of the effect of pentadecapeptide BPC 157 in Parkinson's disease models in mice and gastric lesions induced by 1-methyl-4-phenyl1,2,3,6-tetrahydrophyridine. J Physiol Paris. 1999;93:505-512.

17. Sikiric P, Separovic J, Buljat G, et al. Gastric mucosal lesions induced by complete dopamine system failure in rats. The effects of dopamine agents, ranitidine, atropine, omeprazole and pentadecapeptide BPC 157. J Physiol Paris. 2000;94:105-110.

18. Sikiric P, Seiwerth S, Grabarevic Z, et al. The beneficial effect of BPC 157 , a 15 amino acid peptide BPC fragment, on gastric and duodenal lesions induced by restraint stress, cysteamine and $96 \%$ ethanol in rats. A comparative study with $\mathrm{H} 2$ receptor antagonists, dopamine promotors and gut peptides. Life Sci. 1994;54:L63-L68.
19. Klicek R, Sever M, Radic B, et al. Pentadecapeptide BPC 157, in clinical trials as a therapy for inflammatory bowel disease (PL14736), is effective in the healing of colocutaneous fistulas in rats: role of the nitric oxide-system. J Pharmacol Sci. 2008;108:7-17.

20. Jandric I, Vrcic H, Jandric Balen M, et al. Salutary effect of gastric pentadecapeptide BPC 157 in two different stress urinary incontinence models in female rats. Med Sci Monit Basic Res. 2013;19:93-102.

21. Cesarec V, Becejac T, Misic M, et al. Pentadecapeptide BPC 157 and the esophagocutaneous fistula healing therapy. Eur J Pharmacol. 2013; 701:203-212.

22. Ilic S, Drmic D, Zarkovic K, et al. Ibuprofen hepatic encephalopathy, hepatomegaly, gastric lesion and gastric pentadecapeptide BPC 157 in rats. Eur J Pharmacol. 2011;667:322-329.

23. Ilic S, Brcic I, Mester M, et al. Over-dose insulin and stable gastric pentadecapeptide BPC 157. Attenuated gastric ulcers, seizures, brain lesions, hepatomegaly, fatty liver, breakdown of liver glycogen, profound hypoglycemia and calcification in rats. J Physiol Pharmacol. 2009;60(suppl 7):107-114.

24. Xue XC, Wu YJ, Gao MT, et al. Protective effects of pentadecapeptide BPC 157 on gastric ulcer in rats. World J Gastroenterol. 2004;10: 1032-1036.

25. Jelovac N, Sikiric P, Rucman R, et al. Pentadecapeptide BPC 157 attenuates disturbances induced by neuroleptics: the effect on catalepsy and gastric ulcers in mice and rats. Eur J Pharmacol. 1999;379: 19-31.

26. Sebecic B, Nikolic V, Sikiric P, et al. Osteogenic effect of a gastric pentadecapeptide, BPC-157, on the healing of segmental bone defect in rabbits: a comparison with bone marrow and autologous cortical bone implantation. Bone. 1999;24:195-202.

27. Lazic R, Gabric N, Dekaris I, Bosnar D, Boban-Blagaic A, Sikiric P. Gastric pentadecapeptide BPC 157 promotes corneal epithelial defects healing in rats. Coll Antropol. 2005;29:321-325.

28. Singh RP, Dhanalakshmi S, Agarwal C, Agarwal R. Silibinin strongly inhibits growth and survival of human endothelial cells via cell cycle arrest and downregulation of survivin, Akt and NF-kappaB: implications for angioprevention and antiangiogenic therapy. Oncogene. 2005;24:1188-1202.

29. Loughlin DT, Artlett CM. 3-Deoxyglucosone-collagen alters human dermal fibroblast migration and adhesion: implications for impaired wound healing in patients with diabetes. Wound Repair Regen. 2009;17: 739-749.

30. Gospodarowicz D. Biological activities of fibroblast growth factors. Ann N Y Acad Sci. 1991;638:1-8.

31. Hayek A, Culler FL, Beattie GM, Lopez AD, Cuevas P, Baird A. An in vivo model for study of the angiogenic effects of basic fibroblast growth factor. Biochem Biophys Res Commun. 1987;147:876-880.

32. Tassi E, Al-Attar A, Aigner A, et al. Enhancement of fibroblast growth factor (FGF) activity by an FGF-binding protein. J Biol Chem. 2001; 276:40247-40253.

33. Tsuboi R, Rifkin DB. Recombinant basic fibroblast growth factor stimulates wound healing in healing-impaired db/db mice. J Exp Med. 1990;172:245-251.

34. Shao R, Guo X. Human microvascular endothelial cells immortalized with human telomerase catalytic protein: a model for the study of in vitro angiogenesis. Biochem Biophys Res Commun. 2004;321:788-794.

35. Mikus D, Sikiric P, Seiwerth S, et al. Pentadecapeptide BPC 157 cream improves burn-wound healing and attenuates burn-gastric lesions in mice. Burns. 2001;27:817-827.

36. Skorjanec S, Dolovski Z, Kocman I, et al. Therapy for unhealed gastrocutaneous fistulas in rats as a model for analogous healing of persistent skin wounds and persistent gastric ulcers: stable gastric pentadecapeptide BPC 157, atropine, ranitidine, and omeprazole. Dig Dis Sci. 2009;54:46-56. 
37. Pevec D, Novinscak T, Brcic L, et al. Impact of pentadecapeptide BPC 157 on muscle healing impaired by systemic corticosteroid application. Med Sci Monit. 2010;16:BR81-BR88.

38. Novinscak T, Brcic L, Staresinic M, et al. Gastric pentadecapeptide BPC 157 as an effective therapy for muscle crush injury in the rat. Surg Today. 2008;38:716-725.

39. Staresinic M, Petrovic I, Novinscak T, et al. Effective therapy of transected quadriceps muscle in rat: Gastric pentadecapeptide BPC 157. J Orthop Res. 2006;24:1109-1117.

40. Krivic A, Majerovic M, Jelic I, Seiwerth S, Sikiric P. Modulation of early functional recovery of Achilles tendon to bone unit after transection by BPC 157 and methylprednisolone. Inflamm Res. 2008; 57:205-210.
41. Cerovecki T, Bojanic I, Brcic L, et al. Pentadecapeptide BPC 157 (PL 14736) improves ligament healing in the rat. J Orthop Res. 2010;28:1155-1161.

42. Chang CH, Tsai WC, Lin MS, Hsu YH, Pang JH. The promoting effect of pentadecapeptide BPC 157 on tendon healing involves tendon outgrowth, cell survival, and cell migration. J Appl Physiol (1985). 2011(110):774-780.

\section{Publish your work in this journal}

Drug Design, Development and Therapy is an international, peerreviewed open-access journal that spans the spectrum of drug design and development through to clinical applications. Clinical outcomes, patient safety, and programs for the development and effective, safe, and sustained use of medicines are a feature of the journal, which has also been accepted for indexing on PubMed Central. The manuscript management system is completely online and includes a very quick and fair peer-review system, which is all easy to use. Visit http://www.dovepress.com/testimonials.php to read real quotes from published authors.

Submit your manuscript here: http://www.dovepress.com/drug-design-development-and-therapy-journal 